\section{QUESTÕES DE GÊNERO E O TRÁFICO DE MULHERES NEPALESAS}

Alice Agnes Spíndola Mota ${ }^{1}$

\section{Gender Issues and Trafficking of Nepalese Women}

\section{RESUMO}

Observando as questões de gênero e os crescentes direitos adquiridos pelas mulheres em todo o mundo nas últimas décadas, este artigo procura analisar situações de riscos ainda vivenciadas pelo gênero feminino no Nepal atualmente. $\mathrm{O}$ estudo focado no tráfico de mulheres para exploração sexual entre o Nepal e a Índia tem como objetivo estudar a importância e significado das questões de gênero neste contexto, bem como sua correlação com aspectos socioeconómicos e culturais ocultos na problemática do tráfico humano. Sem contudo propor análise e compreensão de todas as dimensões do mercado de prostituição feminina entre Nepal e Índia o trabalho propõe uma reflexão sobre a realidade feminina contemporânea nestes países asiáticos.

Palavras-chave: Tráfico, Gênero, Exploração, Nepal, Índia.

\section{ABSTRACT}

Noting gender issues and the increasing rights acquired by women around the world in recent decades, this article seeks to analyze risk situations still experienced by females in Nepal today. The study focused on the trafficking of women for sexual exploitation between Nepal and India aims to study the importance and significance of gender in this context as well as its correlation with socio-economic and cultural aspects hidden in the problem of human trafficking. Not aiming to analyze and understand all dimensions of the female prostitution market between Nepal and India, this work proposes a reflection on the contemporary women's reality in these Asian countries.

Keywords: Trafficking, Gender, Exploration, Nepal, India.

1 - Jornalista e Mestre em Desenvolvimento pela Universidade Federal do Tocantins, aluna do curso de doutorado em Antropologia do ISCTE. aliceagnes.to@gmail.com - (063) 8402-3459 


\section{INTRODUÇÃO}

Os avanços tecnológicos em ritmo acelerado transcenderam barreiras geográficas e culturais nas últimas décadas refletindo-se em transformações sociais de escala global fortemente marcadas por discussões entre o universalismo dos direitos humanos básicos e o relativismo cultural. Neste contexto de complexa dualidade entre generalizações e idiossincrasias, as questões de gênero tornaram-se temáticas em crescente evidência mundial. O ingresso das mulheres no mercado de trabalho, a luta pelos direitos de equidade entre os sexos, a queda dos índices de fertilidade em dimensões mundiais, e até mesmo as mudanças referentes ao vestuário feminino são algumas situações exemplificadoras dos paradoxos que reúnem direitos elementares e convenções culturais no mesmo plano de discussões.

As mudanças e transições dos antigos papéis estratificados simbólicos de homem e mulher na sociedade no decorrer da história refletiram-se diretamente em transformações culturais, economicas, políticas e religiosas, dentre outras. É público e notório o fato de que ainda existem diversas situações de opressão às mulheres em várias partes do mundo, mas é importante ressaltar também a existência de mulheres desempenhando papéis históricos proeminentes nas mais antigas sociedades, como por exemplo a mulher faraó Hatshepsut Makare que governou o Egito de 1479 de 1458 aC, ou mesmo de Joana d'Arc ao liderar exércitos em 1429 d.C . Mediante a evolução histórica do papel da mulher na maioria das sociedades, e também sob a influência da intensificação da luta pelos direitos das mulheres no século XIX, as questões de gênero adquiriram maior evidência e as reivindicações pelo fim da opressão feminina ganharam perspectivas globais. Embora as mulheres sejam atualmente minoria na população mundial, havendo 57 milhões de homens a mais, ${ }^{3}$ nunca se discutiu tanto a necessidade de proteção e igualdade de direitos deste grupo como no presente século.

Cabe ressaltar que em sociedades mais antigas e tradicionais o conceito de igualdade entre os sexos evidentemente encontrou uma resistência maior do que nas demais, e neste sentido destaca-se o continente asiático como colecionador dos maiores índices de violência contra a mulher, ${ }^{4}$ mortalidade, pobreza e analfabetismo feminino, o que o torna por conseguinte alvo central de constantes estudos e investigações sobre às questões de gênero, cultura e direitos humanos.

A Índia como maior e mais populoso país do continente asiático, é também a responsável por algumas das piores estatísticas referentes à população feminina, dentre as quais destacam-se a prostituição involuntária, tráfico e exploração infantil com ponto de origem no Nepal, país vizinho de inversas proporções. Estima-se que anualmente cerca de 12 mil mulheres (com idades a partir de onze anos) sejam comercializadas do Nepal para Índia com fins de prostituição.

Para compreender a dimensão do problema do tráfico feminino entre Nepal e Índia, especialmente o que envolve crianças, faz-se necessário primeiramente compreender as relações e condições destes países, como parte fundamental do processo. Para Kumar, o tráfico para prostituição pode ser explicado em grande parte através da contextualização socioeconômica do Nepal:

Nepal, um dos países menos desenvolvidos do mundo, está se esforçando para acelerar o ritmo de desenvolvimento socioeconômico no contexto de um sistema

2 - De acordo com o relatório The World's Women "In Europe, the average age at which women first marry is 30 or older in many countries. In some less developed countries, however, such as Mali, Niger and several other countries in sub-Saharan Africa, the average age at which women first marry is still below 20. As familybuilding often starts with a marriage, the consequences for fertility is obvious. Globally, fertility declined to 2.5 births per woman, but women who bear more than five children are still common in countries where women marry early." (ONU 2010, p.vii)

3 - "Este excedente de homens está concentrado nos grupos etários mais jovens e diminui progressivamente até desaparecer por volta dos 50 anos de idade, originando, posteriormente, um excedente de mulheres devido a sua expectativa de vida mais longa. O excedente de homens é característico nos países mais populosos do mundo China e Índia - daí o grande excedente de homens em todo o mundo. Na maioria dos outros países, há mais mulheres do que homens" (ONU 2010, p. vii - tradução da autora)

4 - A Ásia possui três dos dez maiores índices mundiais de violência contra a mulher e aparece em dezoito colocações no ranking de "proportion of women experiencing intimate partner physical violence at least once in their lifetime and in the last 12 months" estando eentre os cinquenta piores índices do mundo. (ONU 2010, p.138)

5 - KUMAR 2001, p.10 
parlamentar multi partidário adotado em 1990. Com uma renda per capita de 210 dólares, Nepal ocupa o $144^{\circ}$ lugar no Índice de Desenvolvimento Humano das Nações Unidas. Quarenta e cinco por cento da população vive abaixo da linha da pobreza. A pobreza, o elevado crescimento populacional, analfabetismo, desemprego e subemprego, problemas de saúde, crescimento economico lento uma economia agrária caracterizam a sociedade nepalesa. (KUMAR 2001, p. 10) ${ }^{6}$

Os índices indianos fazem severo contraste com os baixos índices nepaleses, sendo a Índia atualmente a quarta maior potência mundial, com PIB de 3,68 trilhões de dólares e renda Per Capita de 3.200 dólares? de acordo com o purchasing power parity. Embora os fatores socioeconómicos nepaleses e indianos não expliquem o problema do tráfico para exploração sexual, auxiliam na compreensão deste fenômeno cuja complexa análise exigiria um extenso e detalhado estudo. O propósito deste artigo não é analisar ou compreender toda as dimensões do mercado de prostituição feminina entre Nepal e Índia, mas sim estudar a importância e significado das questões de gênero neste contexto, bem como sua correlação com aspectos socioeconómicos e culturais ocultos na problemática do tráfico humano. A exploração sexual infantil feminina detém a esmagadora maioria do mercado do sexo na Índia e Nepal e não é vista nestes lugares sob a mesma ótica do mundo ocidental capitalista, que considera tal prática de caráter criminoso e essencialmente de afronta aos direitos humanos básicos. Atualmente, mediante pressões externas e diplomáticas, Índia e Nepal posicionaram-se oficialmente contra a exploração sexual infantil, mas este problema de profundas raízes históricas permanece detentor de números impressionantes.

\section{2- OSEXO FEMININO NO NEPAL}

O Nepal foi até 2006 o único país do mundo cuja religião oficial era o hinduísmo, entretanto após a instalação do regime democrático, mediante guerra civil e inúmeras disputas políticas, o país tornou-se oficialmente laico. Apesar de ser um dos mais pobres países da Ásia, o Nepal possui uma das maiores densidades demográficas do continente com 153 habitantes por quilometro quadrado, sua economia está baseada principalmente na agricultura, e a população de 23 milhões de habitantes divide-se em um vasto sistema étnico de 12 grupos, reunindo diferentes povos, costumes e culturas em um pequeno espaço geográfico. Para Shresta (2003) o Nepal é um território de muitas minorias.

Com apenas 23,2 milhões de habitantes e medindo apenas 147.181 quilômetros quadrados, o Nepal é palco de 62 "nacionalidades" (janajati). Nenhuma dessas nacionalidades, incluindo a população Khas predominante - que consiste em castas brâmane-Ksetri, falando Nepali (Khas) e praticando o hinduísmo - pode ser considerada como um único grupo majoritário (SHRESTHA, 2003,p.1)

Em meio a um conturbado cenário político e socioeconómico, a maior parte da população nepali enfrenta escassez ou privação de serviços elementares como alimentação, moradia, saneamento e educação, fatores estes que contribuem na acentuação da discriminação de gênero. Em 2001 Bal Kumar pesquisou 72 grupos e famílias no Nepal, e outras 49 meninas foram investigadas em processos de reabilitação após o resgate de situações de prostituição e risco em 10 cidades diferentes de Nepal, e com base nos dados obtidos descobriu que a pobreza e restrição educacional são alguns dos principais fatores de contribuição para o tráfico de meninas, tendo também o sistema de castas uma grande influência neste processo.

A discriminação de gênero começa na infância e afeta particularmente as meninas. Elas são impedidas de alcançar a educação básica e, depois do casamento, a nora tem menos poder e status na família. A discriminação de gênero é amplamente citada como a causa do tráfico de meninas. [...] A esmagadora maioria dos pais de meninas traficadas são analfabetos, especialmente as mães [...] meninas traficadas são em grande parte provenientes de famílias analfabetas, particularmente quando há mães irmãs analfabetas. (KUMAR, 2003, p.46)

6 - Tradução da Autora

7 - CENTRAL INTELLIGENCE AGENCY - The World Fact Book. 2009.

8 - Em 21 de novembro de 2006, o governo transitório do Nepal assinou com líderes rebeldes maoístas um acordo de paz, pondo fim a um conflito iniciado em 1996. Sete dias depois, assinaram um novo acordo estabelecendo as regras do desarmamento das forças insurgentes, sob inspeção da ONU. (SILVA, 2006, p.2)

9 - WORLD STATICS. List of Countries by Land Mass "Ranked by Area". 2008

10 - Tradução da Autora

11 - Tradução da autora.

Divers@ Revista Eletrônica Interdisciplinar / Matinhos /

Vol.6, n.1, p.1-77 
A privação educacional é um dentre os muitos fatores que comprovam a inferiorização da mulher nepali na sociedade. O elevado número de etnias e o sistema de castas são outras questões que contribuem para a discriminação feminina em diversas perspectivas. A cultura, a religião e até mesmo algumas leis estão relativamente condicionadas a tratar a mulher como indivíduo inferior, dependente ou obrigatoriamente submisso ao sexo masculino. A urgente necessidade de proteção e amparo ao gênero feminino no Nepal pode ser também observada através da existência de 4.175 ONG's de serviço à mulher, ${ }^{12}$ que comprovam a urgente necessidade de proteção do sexo feminino no país. O pouco respaldo no contexto familiar e legal são elementos que contribuem para a vulnerabilidade das mulheres nepalis. Rita Manchanda, chama a atenção para alguns aspectos legais que reforçam o preconceito contra o gênero feminino no Nepal.

Como um índice para as diversas perspectivas de opressão que se vinculam às mulheres nepalesas, especialmente no modelo da mulher de casta hindu superior, há um ditado popular: "Se minha próxima vida é ser a vida de um cão, eu prefiro ser um cão do que uma puta ". O perfil de gênero do Nepal revela que as mulheres sofrem de 54 leis discriminatórias, incluindo a cidadania e herança. O tempo de vida de uma mulher é mais curto por dois anos e meio. A taxa de mortalidade materna do Nepal é de 905 para cada 100.000, igualada apenas ao Afeganistão; as mulheres assistir um em cada nove filho morrerem em menos de cinco anos. Isto é acompanhado por casamentos precoces, casamentos precoces, gravidezes múltiplas para gerar filhos e, assim, garantir a vida conjugal e sua parcela de terra através de filhos. As mulheres não têm direito a uma parte igual de propriedade dos pais (apenas mulheres solteiras com mais de 35 anos), nem podem herdar direitos de arrendamento e, portanto, acessar empréstimos bancários e etc (MANCHANDA, 2008, p.5) ${ }^{13}$

A mulher nepali é refém de um sistema no qual as propabilidades de progresso feminino, seja educacional, econômico ou social, são estritamente limitadas. No serviço civil, por exemplo, as mulheres representavam até o ano de 2000 menos de $8 \%$ do total de servidores. ${ }^{14}$ Outro índice que exemplifica o papel subalterno da mulher no Nepal é a taxa de fertilidade cuja média é de 5 filhos por mulher, sendo que, quando uma mulher não engravida nos três primeiros anos do casamento seu marido tem direito de casar novamente e abandoná-la, o que muitas vezes torna-se um motivo para a inserção no mercado de prostituição. ${ }^{15}$ Para além de tais questões, o próprio regime familiar patriarcal expressa claramente o papel de destaque e predileção que os homens tem em relação às mulheres, desde cedo as meninas são privadas do direito à voz na família enquanto os meninos são incentivados a participar das decisões. ${ }^{16}$

Ser mulher no Nepal comumente significa não ter autonomia de decisão sobre a própria vida, desde a fase inicial de sua vida a mulher aprende a viver sob a direção e vontade dos pais e uma vez casada, sob os cuidados do marido, situação esta que torna-se ainda mais complicada para mulheres pertencentes a baixas castas. Na maioria dos casos, mesmo em suas próprias famílias as mulheres ocupam desde o nascimento o papel de objeto-mercadoria, prova disso é que o tráfico para prostituição infantil feminino se dá, geralmente, com o consentimento dos familiares que realizam uma transação comercial, a garota vendida no Nepal por um valor irrisório é posteriormente revendida a um bordel indiano por um valor cinco vezes maior e obrigada a trabalhar ali em sistema escravagista até remunerar o patrão-dono a quantia monetária gasta em sua aquisição. Cabe ressaltar que nem sempre a família está consciente do futuro destinado à garota que é inserida no mercado de prostituição, muitas vezes os traficantes casam-se com as jovens e uma vez que as tiram de suas casas, atravessam a fronteira para comercializá-las nos bordéis indianos. Para fins de análise e estudo, o tráfico infantil para exploração sexual pode ser dividido pragmaticamente em dois tipos, soft em hard, os quais Bal Kumar define da seguinte forma:

12 - NEPAL REPORT. Report on the State of Women in Urban Local Government Nepal. 2000.

13 - Tradução da autora.

14 - No serviço público as mulheres são indicadas para serviços até na classe especial, mas em um número muito insignificante. Até o ano 2000 apenas 2 senhoras tiveram a sorte de serem nomeadas em classe especial. Este valor correspondeu a apenas 2,35 por cento do total de nomeações de classe especial. Entre os funcionários públicos de primeira classe, as mulheres constituem 4,10 por cento, 3,16 por cento de segunda classe e 5,24 por públicos de primeira classe, as mulheres constituem 4,10 por cento, 3,16 por cento de segunda classe e 5,24 por
cento das mulheres da terceira classe de oficiais do país. (NEPAL Report, 2000, p. 10 - tradução da autora) cento das mulheres da terceira classe de oficiais do país. (NEPAL Report, 2000, p. 10 - tradução da autora)
15 - Em áreas rurais remotas, o sistema de castas hierárquica é fundamentalmente excludente. As pessoas de casta inferior enfrentam a exploração econômica, a discriminação social e de alto risco de exploração sexual. Em entrevista, uma garota da casta intocável, informou que homens de castas superiores a obrigaram a se prostituir. Foi-lhe dito que esta era sua ocupação de castas. (KUMAR, 2001, p. 46 - tradução da autora)

16 - [...]A sociedade dá prioridade à criança do sexo masculino, porque ele vai ganhar o sustento para a família e ele será responsável por cuidar dos pais na velhice. Assim, a sua participação na tomada de decisões nos assuntos familiares é necessária ao passo que a menina é treinada para realizar trabalhos domésticos. (Nepal Reports, 2000, p. 8 - tradução da autora)

\footnotetext{
Divers@

Revista Eletrônica Interdisciplinar

/ Matinhos
}

I

Vol.6, n.1, p.1-77

I

jan./jun./2013

ISSN 1983-8921 
A distinção entre o soft traffcking e hard traficking se refere à coerção e / ou cumplicidade dos membros de uma família nuclear e / ou família envolvida na entrada de uma pessoa para a prostituição forçada ou de menores de idade. Estas nomenclaturas não se referem ao padrão de movimento ou papéis desempenhados. No soft trafficking, os membros da família nuclear e / ou parentes distante podem desempenhar um papel além do de vendedor, incluindo transportador e comprador (se a pessoa é enviado para trabalhar em um estabelecimento de propriedade da família). A maioria dos pais da pesquisa deu consentimento silencioso ou foi de alguma forma envolvido no tráfico de suas filhas. As meninas são frequentemente vistas como mercadorias da família que, como propriedade, podem ser comprados e vendidos. (KUMAR, 2003, p. 10-11) $)^{17}$

Novamente as questões de gênero mostram-se de fundamental relevância no estudo do tráfico humano entre Nepal e Índia, pois embora seja comumente identificada a presença de soft traffcking de meninas, não existem registros de situações nas quais as famílias comercializem meninos, mesmo que tal prática possa ocorrer esporadicamente, não é recorrente ao ponto de ser detectado ou reconhecido como comportamento social. A aceitação cultural do tráfico para exploração sexual na sociedade nepali é um dos maiores obstáculos ao combate desta realidade, pois esta prática tornou-se parte da cultura local, ao ponto do tráfico para os bordéis indianos ser considerado por muitas mulheres como uma opção de progressão social. ${ }^{18}$

O casamento é comumente a forma encontrada por alguns homens e famílias para adquirirem "mulheres-escravas", uma menina pode ser dada em casamento ainda muito nova e a partir de então é obrigada a diversos tipos de trabalhos domésticos, existindo ainda a possibilidade de comercialização da mesma como fonte de renda para o homem que a desposou e o risco de divórcio cujo resultado para as mulheres é geralmente o total abandono e a prostituição como única opção de sobrevivência. ${ }^{19} A$ respeito desta questão KUMAR (2001:45) observa em seus estudos que "Em alguns países, o fenômeno de perceber o casamento como uma forma de aumentar a força de trabalho familiar ou de enviar uma menina para trabalhar fora e enviar de volta o dinheiro, tem sido nomeado mercantilização das meninas". ${ }^{20}$ Existe no
Nepal uma parcela da população que considera os indivíduos do sexo feminino nada mais do que uma mercadoria de baixo valor.

\section{3- OTRÁFICO DE MENINAS}

O problema do tráfico de seres humanos aflige diversos países em todo o mundo e pode ter variados propósitos, desde a exploração em trabalhos braçais à exploração sexual. A Organização das Nações Unidas apresenta a seguinte definição para tráfico de pessoas:

[...]O recrutamento, transporte, transferência, alojamento ou recepção de pessoas, mediante ameaça, uso da força ou de outras formas de coação como o rapto, fraude, engano, abuso de poder ou de uma posição de vulnerabilidade, suborno ou troca de benefícios para obter o consentimento de uma pessoa que tenha autoridade sobre outra, para fins de exploração. (United Nations General Assembly, 2000, p. 3).

Apesar da relativa aceitação local em relação ao tráfico de pessoas no Nepal e na Índia, a exploração sexual de meninas e mulheres tem consequências sociais que vão muito além da dialética cultura versus direitos humanos, dentre estas cabe ressaltar o aumento das taxas de mortalidade e a propagação do vírus da HIV.

17 - Tradução da autora.

18 - "Uma dos nossos principais informantes femininas explica por que as meninas são traficadas de sua aldeia de Sindhupalchowk. "Se formos para a Índia nos sentimos felizes. Se ficarmos aqui, ninguém nos dá um único centrovo Rita uma das nosas vizinhas, foi enviada para á Í dia por su marido e la ficou lá por tấs unnico centavo. Rita, uma das nossas vizinhas, foi enviada para a India por seu marido e ela ficou lá por três anos, ela voltou com uma quantia considerável de dinheiro. Eles construíram uma boa casa na aldeia e em Kathmandu. Eles também têm emprestado dinheiro na aldeia. Com a renda destes empréstimos, eles comem arroz. Todos os respeitam. Mesmo que tenhamos problemas de saúde quando nos tornamos mais velhas, podemos gerir do dinheiro obtido na Îndia. Ah! Eu teria ido lá se o meu marido me mandasse”" (BAL KUMAR 2001, p.45 tradução da autora)

19 - Sawana, mulher oriunda de uma família muçulmana, tinha apenas sete anos quando se casou e treze anos quando deu à luz seu primeiro filho. Quando o bebê tinha apenas um mês de idade, seu marido divorciou-se dela. Com a ajuda de amigos, ela se envolveu na prostituição para ganhar o suficiente para sobreviver. Agora aos 18 Sawana permanece na prostituição em Nepalgunj. Seu salário serve de sustento para ela, sua mãe de sessenta anos de idade e seu filho de cinco anos (BAL KUMAR 2001, p.45 - tradução da autora)

20 - Tradução da autora. 
As garotas comercializadas para exploração sexual geralmente possuem idade inferior a dezoito anos e são submetidas a condições sub-humanas nos bordéis, se tentam fugir são punidas com crueldade, não recebem quaisquer remunerações por seus serviços além de alimentação e moradia elementar, no caso de gravidez ou aquisição de doença são imediatamente despejadas. Em média gastam de 13 a 24 horas por dia em prostituição e são forçadas a atender um mínimo de três clientes por dia, podendo este número variar até quarenta. ${ }^{21}$

Mesmo havendo a definição de duas distintas tipologias de tráfico feminino para exploração sexual, os destinos são geralmente semelhantes.2. Dentre as muitas maneiras pelas quais garotas são inseridas no tráfico de prostituição estão falsas promessas de casamento, emprego, renda, comida e drogas. Em muitos casos pode ser difícil a distinção entre traficantes, negociadores externos e falsos maridos. A maioria "das meninas são traficadas por “corretores" externos $(52,2 \%)$, seguido por "corretores" locais $(23,9 \%)$, parentes próximos $(13,4 \%)$, maridos falsos $(6,0 \%)$ e colegas de trabalho $(4,5 \%)^{23}$. Dentre os muitos modos pelos quais as meninas estão inseridas no tráfico da prostituição estão falsas promessas, como o casamento, o emprego, bem como alimentos e alguma renda ou drogas. Em muitos casos, pode ser difícil distinguir entre os traficantes, os corretores de fora, parentes e maridos falsos

Uma grande barreira do combate ao tráfico de prostituição do Nepal para a Índia está nas concepções sobre o sexo feminino em ambas as nações, embora note-se uma gradual transformação nos paradigmas de gênero nestes países, a inferioridade da mulher em relação ao homem ainda é um conceito existente. Existem muitos grupos na luta pelos direitos femininos na Índia e Nepal, e é notável a presença emergente de mulheres na política e economia, entretanto, não obstante tais fatos, um estudo sobre o feminismo na Índia feito pelos autores Tharu e Niranjana observou que o gênero feminino encontra-se ainda inferiorizado, mesmo diante dos mais variados sistemas de divisão social.

O problema é que uma série de questões constituem a subjugação das mulheres, e de em relação à classe, casta e co pertencem, é naturalizada na "mulher" cuja liberdade e direito à privacidade são invocados e que se torna a portadora do "direito" de escolher (THARU; NIRANJANA 1999, p. 264$)^{24}$

É possível afirmar com base nas colocações supracitadas que um dos principais alicerces do tráfico de prostituição feminina entre Nepal e Índia não é a pobreza, a vulnerabilidade da infância ou a pouca instrução, mas sim o pensamento empírico popular de que as mulheres são um bem à disposição de seus familiares do sexo masculino, os quais podem atribuir-lhes a função que julgarem necessária ou simplesmente conveniente. $\mathrm{O}$ governo do Nepal e inúmeras ONG's têm empenhado um crescente esforço no combate ao tráfico e exploração de meninas no país na última década, mas são muitas as barreiras encontradas, especialmente no que diz respeito às questões políticas e corrupção da polícia. Em sua pesquisa sobre o tráfico de meninas no Nepal, BAL KUMAR e sua equipe chegaram à conclusão de que "a proteção de criminosos por partidos políticos pode ser amplamente observada [...] Parece ser do conhecimento comum que, quando os criminosos do tráfico são presos, eles são liberados através de amigos influentes a nível nacional". ${ }^{25}$ Embora existam alguns poucos partidos políticos com programas contra tráfico de meninas, diante de eminentes disputas e rebeliões políticas, a questão da exploração sexual infantil não está entre as principais discussões de interesse público ou dos líderes representantes.

Apesar dos prejuízos sociais acarretados pelo tráfico de meninas, tal problema não é considerado prioridade nem mesmo para o governo, que em um país afligido por diversos outros problemas sociais opta por restringir o combate ao tráfico sexual a limitadas estratégias, muitas vezes ineficazes diante da corrupção no próprio sistema de governo.

21 - KUMAR, 2001, p. 11

22 - A maioria das meninas foi traficada por corretores externos $(52,2 \%)$, seguido por corretores locais $(23,9 \%)$ parentes próximos $(13,4 \%)$, maridos falsos $(6,0 \%)$ e colegas de trabalho (4,5\%). (BAL KUMAR 2001, p. 30 tradução da autora)

23 - KUMAR, 2001, p. 30

24 - Tradução da Autora

25 - KUMAR, 2001, p. 46 - tradução da autora 


\section{4- CONCLUSÃO}

As garotas e mulheres comercializadas no tráfico sexual, quando conseguem sobreviver ao período de exploração e semiescravidão, veem-se obrigadas a lidar com as sérias consequências da vida no bordel, que variam desde doenças sexualmente transmissíveis à gravidez indesejada, isolamento social, rejeição por parte da família, abandono e outros. O destino destas meninas é complexo e diversificado, poucas retornam para suas casas, algumas são acolhidas por instituições filantrópicas ou centros de reabilitação e um bom número acaba regressando à prostituição como única alternativa encontrada para sobrevivência.

As limitações impostas ao gênero feminino na sociedade nepali, condicionam a prostituição como uma das poucas alternativas viáveis para subsistência de uma mulher fora da tutela de um homem. A pouca instrução educacional da grande maioria feminina e um preconceituoso mercado de trabalho, são fatores que dificultam a busca por emprego, mesmo sendo o Nepal um país majoritariamente rural e de economia agrícola.

Até mesmo nos casos em que garotas traficadas conseguem abandonar a prostituição e obter uma fonte de renda "lícita", os danos psicológicos, morais e físicos impossibilitam a retomada de uma vida normal. Ao pesquisar um grupo de 128 garotas nepalis resgatadas de um bordel em Bombaim, BAL KUMAR e sua equipe de pesquisadores observaram que "maioria das meninas reintegradas e reabilitadas não estão levando uma vida normal devido a percepção das crenças e atitudes em relação à essas meninas na sociedade". ${ }^{26}$

A questão do tráfico de meninas nepalis para exploração sexual na Índia deve não apenas ser reconhecido e combatido, mas compreendido em todas as suas dimensões, uma vez que trata-se de uma prática muito mais complexa do que um mero fênomeno social, tendo suas raízes profundamente alicerçadas nas questões de gênero, que por sua vez estão fortemente entranhadas à cultura, história e economia da região. Para acabar com a rota de prostituição nas fronteiras sul-asiáticas é necessária a aceitação da existência dos direitos femininos e o reconhecimento do valor da mulher como ser humano e não mero objeto comercializável. Medidas políticas como rigorosa aplicação da lei de combate ao tráfico de seres humanos e aumento da fiscalização das fronteiras são também de fundamental importância, mas correm o risco de tornarem-se meramente paliativas caso profundas mudanças estruturais não aconteçam.

A trágica realidade da opressão feminina através do mercado da prostituição torna ainda evidente a urgência de melhorias educacionais para o povo nepali cuja população é composta por mais de $51 \%$ de analfabetos, ${ }^{27}$ para além disto, faz-se necessária a transformação da mentalidade popular no que diz respeito à importância da mulher, seus papéis e direitos na sociedade. Sem que ocorram radicais mudanças na forma de ver e pensar o gênero feminino no Nepal, sempre existirão baixas perspectivas e inúmeros temores a assombrar o futuro das mulheres nepalis desde o dia de seus nascimentos.

\section{REFERENCIAS BIBLIOGRÁFICAS}

ACSSA BRIEFING. The 'Trafficking Protocol' Definitions and interpretations. Australian Institute of Family Studies. 2005 . Dis ponível e m: $<$ http://www.aifs.gov.au/acssa/pubs/briefing/b5pdf/acssa brief5 protocol.pdf $>$ Acesso em 8 dez. 2010

CENTRAL INTELLIGENCE AGENCY - CIA. The World Fact Book. 2010. Disponível em: <https://www.cia.gov/library/publications/the-world-factbook/geos/in.html> Acesso em 10 dez. 2010

IN DEX MUNDI. Nepal Literacy. 2010 . Disponível em: <http://www.indexmundi.com/nepal/literacy.html> Acesso em $10 \mathrm{dez} .2010$

KUMAR KC, Bal. Nepal Trafficking in Girls With Special Reference to Prostitution: A Rapid Assessment. Geneva: CDPS, 2001

26 - KUMAR, 2001, p. 39 - tradução da autora

27 - INDEX MUNDI, 2010 
MANCHANDA, Rita - Women's Question In Nepal's Democratic Post Conflict Transition : Towards A Policy Research Agenda. 2008. Peace Prints: South Asian Journal of

Peacebuilding, v. 3, $\mathrm{n}^{\circ} 1$, Spring 2010

NEPAL REPORT - Report on the State of Women in Urban Local Government Nepal. 2000. Disponível em: $<\geq$ Acesso em 8 dez. 2010

SHRESTHA, Bal Gopal - Ethnic Nationalism in Nepal. Researchers and Reports. Rapenburg: International Institute for Asian Studies, Number 30, 2003

SILVA, Frederico de Faria e. Anunciado fim da guerra civil no Nepal. Conjuntura Internacional, Belo Horizonte, v.1, n 35, p. 2-5, 2006

THARU, Susan; NIRANJANA, Tejaswini. Problems for a Contemporary Theory of Gender. In "Gender and politics in Índia". Delhi: Oxford University Press, 1999

THE WORLD'S WOMEN 2010, Trends and Statistics. Department of Economic and Social Affairs. New York: United Nations, 2010.

WORLD STATICS - List of Countries by Land Mass "Ranked by Area". 2008. (Acesso em 9 dez. 2010) Available at http://www.mongabay.com/igapo/world_statistics_by_area.htm 